\title{
Limitations of integrated assessment models of climate change
}

\author{
Frank Ackerman • Stephen J. DeCanio • \\ Richard B. Howarth • Kristen Sheeran
}

Received: 17 March 2008 / Accepted: 10 December 2008 / Published online: 2 April 2009

(C) The Author(s) 2009. This article is published with open access at Springerlink.com

\begin{abstract}
The integrated assessment models (IAMs) that economists use to analyze the expected costs and benefits of climate policies frequently suggest that the "optimal" policy is to go slowly and to do relatively little in the near term to reduce greenhouse gas emissions. We trace this finding to the contestable assumptions and limitations of IAMs. For example, they typically discount future impacts from climate change at relatively high rates. This practice may be appropriate for short-term financial decisions but its extension to intergenerational environmental issues rests on several empirically and philosophically controversial hypotheses. IAMs also assign monetary values to the benefits of climate mitigation on the basis of incomplete information and sometimes speculative judgments concerning the monetary worth
\end{abstract}

F. Ackerman

Stockholm Environment Institute-US Center,

Tufts University, Somerville, MA 02144, USA

S. J. DeCanio $(\varangle)$

UCSB Washington Program, 1608 Rhode Island Avenue, NW,

Washington, DC 20036, USA

e-mail: decanio@econ.ucsb.edu

S. J. DeCanio

Department of Economics, University of California, Santa Barbara,

Santa Barbara, CA 93106, USA

R. B. Howarth

Environmental Studies Program, Dartmouth College,

HB 6182, 113 Steele Hall, Hanover, NH 03755, USA

K. Sheeran

Economics for Equity and the Environment Network - a program of Ecotrust,

721 NW Ninth Avenue, Portland, OR 97209, USA

K. Sheeran

Economics Department, St. Mary's College of Maryland,

18952 E. Fisher Rd, St. Mary's City, MD 20686-3001, USA 
of human lives and ecosystems, while downplaying scientific uncertainty about the extent of expected damages. In addition, IAMs may exaggerate mitigation costs by failing to reflect the socially determined, path-dependent nature of technical change and ignoring the potential savings from reduced energy utilization and other opportunities for innovation. A better approach to climate policy, drawing on recent research on the economics of uncertainty, would reframe the problem as buying insurance against catastrophic, low-probability events. Policy decisions should be based on a judgment concerning the maximum tolerable increase in temperature and/or carbon dioxide levels given the state of scientific understanding. The appropriate role for economists would then be to determine the least-cost global strategy to achieve that target. While this remains a demanding and complex problem, it is far more tractable and epistemically defensible than the cost-benefit comparisons attempted by most IAMs.

\author{
Abbreviations \\ $\mathrm{CO}_{2} \quad$ carbon dioxide \\ DICE Dynamic Integrated model of Climate and the Economy \\ GDP Gross Domestic Product \\ GHGs greenhouse gases \\ IAMs Integrated Assessment Models \\ IPCC Intergovernmental Panel on Climate Change \\ US United States
}

\title{
1 Introduction
}

The scientific consensus on climate change is clear and unambiguous; climate change is an observable phenomenon with the potential for catastrophic impacts (Intergovernmental Panel on Climate Change 2007a). The large-scale computer models that helped build this consensus have acquired a good reputation in the scientific community. The leading general circulation models (GCMs) demonstrate ever more detailed and extensive descriptions of the physical processes of climate change, which are testable either directly, or indirectly through "backcasting" of historical climate data. These models are grounded in physical laws that are well-established both theoretically and empirically, although significant uncertainty surrounds key parameters such as the climate sensitivity.

Economists also employ multi-equation computer models in their approach to climate change. These models, known as integrated assessment models (IAMs), build on the results of GCMs to assess the benefits and costs of climate policy options. Economists use IAMs to identify the "optimal" policy response, the option that maximizes the difference between benefits and costs (i.e., net benefits). As the debate over climate policy shifts from scientific uncertainty to economic feasibility, the results of IAMs grow in importance. Interpreting IAMs properly is critical for scientists and others who support a proactive response to the climate problem.

The results of most IAMs are surprising. While many scientists advocate more stringent emissions targets aimed at stabilizing atmospheric greenhouse gas (GHG) 
concentrations during this century, recent IAMs suggest a cautious approach that involves only modest early action to limit emissions with the limits gradually becoming more stringent over time (Kelly and Kolstad 1999; Tol 2002a; Manne 2004; Mendelsohn 2004; Nordhaus 2007a). For example, the optimal emissions reduction rate according to Nordhaus' most recent version of the widely cited DICE model is only $14 \%$ compared to a "business-as-usual" or no-control emission scenario in 2015, rising to $25 \%$ by 2050 and $43 \%$ by 2100 (Nordhaus 2007a). Other IAMs have estimated a positive net benefit from climate change in Organisation for Economic Co-operation and Development countries (while acknowledging net losses in poor countries), leading researchers like Tol to conclude that "climate change and greenhouse gas abatement policy is essentially a problem of justice" (Tol 2002b). On the other hand, it has been estimated that the recently considered suite of Congressional proposals to limit carbon emissions to $50-80 \%$ below 1990 levels by 2050 would impose large welfare losses on the US economy. ${ }^{1}$

How can we reconcile the apparent disconnect between science, which provides an objective characterization of the potentially catastrophic implications of climate change, and economics, which claims that aggressively mitigating climate change is too costly? We maintain that IAMs enjoy an epistemic status different from their natural science counterparts, and that economic models mix descriptive analysis and value judgments in ways that deserve close and critical scrutiny. To build their models, economists have had to embrace assumptions that reflect long-standing practices within economics but that nonetheless are associated with well-known conceptual problems. Alternative models, built on different assumptions that are equally as plausible as those embedded in commonly cited IAMs, would lead to qualitatively different results (Cline 1992; Stern 2006; Ackerman and Finlayson 2006).

Scientific understanding of the climate system is continuously improving. For example, the review article by Hall and Behl (2006) highlights the consequences of climate instability and rapid large-scale shifts in global climate for the economic analysis of climate change. Lenton et al. (2008) identify and catalogue potential "tipping elements" in the climate system. In addition, a variety of decision-making frameworks extending beyond the conventional utility-maximizing economic component of IAMs have been identified (Toth et al. 2001). These include "tolerable windows" and "safe landing" approaches, "robust decision-making," and "costeffectiveness analysis," among others. A recent conference was devoted to the implications of "avoiding dangerous anthropogenic interference with the climate system" as a guide to policy-making (Schellnhuber et al. 2006). Our objective in this article is not to provide a comprehensive review of the most recent developments in climate science $^{2}$ or an all-encompassing treatment of decision-making with regard to climate. Rather, our critique focuses on the conceptual economic framework of the most common utility-maximizing IAMs and on the specific details of how these models

\footnotetext{
${ }^{1}$ The Lieberman-McCain, Feinstein, Kerry-Snowe, and Sanders-Boxer bills specify reductions of 50-80\% below 1990 emissions levels by 2050. US emissions are now 15\% above their 1990 levels. A recent MIT assessment of the congressional cap-and-trade proposals estimated net welfare losses ranging up to about 2\% of GDP by 2050 (Paltsev et al. 2007).

${ }^{2}$ Examples of articles dealing with the kinds of issues treated by Hall and Behl (2006) include Kennedy et al. (2008), Hoegh-Guldberg et al. (2007), and Buffett and Archer (2004).
} 
represent climate costs and benefits. We identify three principal areas in which the standard economic approach is arguably deficient: the discounted utility framework, which attaches less weight to future outcomes; the characterization and monetization of the benefits of mitigation; and the projection of mitigation costs, which rests on assumptions about the pace and nature of technical change. We address these issues in the following three sections and conclude with recommendations for an alternative approach to the economics of climate change that reflects recent advances in the economics of uncertainty.

\section{The discounted utility framework}

IAMs, like the economic theory from which they are derived, start from a particular understanding of human nature and preferences and seek to identify the choices that will maximize the satisfaction of those desires. Climate outcomes enter the analysis as factors that increase or decrease human satisfaction. The "optimal" target is not a safe or pre-determined climate stabilization level, but rather the maximum subjective satisfaction.

Echoing nineteenth century utilitarian moral philosophy, economists refer to satisfaction as "utility" and assume it to be a scalar variable-in short, an ideal objective for maximization. This stylized psychological model, as it has been elaborated in economics, requires careful estimation and comparison of benefits and costs. To compare utilities across generations, economists invoke assumptions about how much additional weight present outcomes deserve over future outcomes. But when economists resort to this technique of discounting the future, the present value of the harms caused by future climate change can easily shrink to the point where it is hardly "worth" doing anything today in order to prevent them.

The basic construct of the typical IAM involves a social welfare function that stretches into the distant future (far enough ahead to experience significant climate change). Frequently, IAMs assume a single representative agent in each generation, or equivalently, that all members of a generation are identical in both consumption and preferences. With slight variations between models, the generic framework is to maximize

$$
W=\int_{0}^{\infty} e^{-\rho t} U[c(t)] d t
$$

where $W$ is social welfare, $\rho$ is the "rate of pure time preference," $c(t)$ is consumption at time $t$, and $U[\bullet]$ is the utility function specifying how much utility is derived from a particular level of consumption. Economists have studied this problem since the time of Ramsey (1928), and the methods they have developed to solve it are now standard elements of the conventional IAM framework. Although this framework dominates the economics of climate change, economists have proposed a number of alternatives (e.g., Howarth and Norgaard 1992; Chichilnisky et al. 1995; Howarth 1998; DeCanio 2003; Bella 2006).

Equation 1 and the techniques required to maximize $W$ embody a large set of questionable assumptions. First note that with $\rho>0$, a given amount of utility occurring further in the future is worth less than the same amount of utility today. This implies that the well-being of this generation matters more than that of its 
children, who in turn matter more than their children. Thus $e^{-\rho t}$ may be interpreted as the relative weighting given to the utility or well-being of various generations. If a generation is 35 years in duration and $\rho=0.05$, the weight given to a unit of utility at the end of the second generation is only $3 \%$ of the weight given to the same unit of utility today. Numerous economists and philosophers since Ramsey have argued that weighing all generations equally, $\rho=0$, is the only ethically defensible practice (for modern treatments, see Cline 1992 and Broome 1994); yet IAMs continue to assume $\rho>0$. This is at least in part a mathematical necessity: with $\rho=0$, the integral in Eq. 1 does not converge if future utility is constant or growing (or merely declining sufficiently gradually) (Dasgupta and Heal 1979).

Second, implicit in the formulation of a social welfare function is the aggregation of preferences across different individuals. In Eq. 1, this aggregation depends only on the total consumption of goods and not on the distribution of that consumption. Whatever method for aggregation is used, it necessarily involves strong and valueladen assumptions. ${ }^{3}$ This is an inescapable consequence of the discounted utility framework. Because the framework requires that preferences be compared and added within and across generations, it forces economists to make normative decisions regarding the comparison of individual utilities and discount rates. Though a social welfare function can be solved mathematically to yield the "optimal" solution, the solution is dependent on the values and biases that are unavoidably embedded in the model and its parameterization.

Third, it is worth noting that the discounted utility characterization of behavior for individuals that underlies this formulation of the social policy problem is not wellsupported by the evidence (Frederick et al. 2002). The optimizing psychological and behavioral assumptions adopted by economic modelers do not have the status of laws of nature. They are matters of convenience and convention, not deep structural features of human action (Laitner et al. 2000; Kahneman and Tversky 2000).

The formulation of Eq. 1 does not include uncertainty about either the consequences of climate change or about the future growth of the economy. This omission is serious, for it is at odds with empirical observations and has strong implications for the treatment of discounting. In this context, it is significant that a recent National Research Council report lists "realistic and credible treatment of uncertainties" as one of its 11 elements of effective assessments (Committee on Analysis of Global Change Assessments 2007). The problems caused by uncertainty can be illustrated by an even simpler version of the decision problem represented by Eq. 1. Our discussion closely follows Cochrane (2005), Mehra (2003) and Howarth (2003, 2009), but the theory is entirely generic. To keep things simple, instead of the infinite horizon

\footnotetext{
${ }^{3}$ One implication of the aggregation method is that if all members of society have equal weight in the social welfare function and all experience diminishing marginal utility to the same degree, the social welfare at any point in time could be increased by redistribution of income from the wealthy to the poor, provided the effects of this redistribution on incentives to produce and save are ignored. An alternate approach-weighting individuals' contribution to social welfare function by their wealth-has obvious drawbacks from an ethical point of view. The same kinds of problems regarding aggregation across individuals and nations plague estimates of the costs of mitigating climate change-the distribution of the costs has a major impact on both the ethical evaluation of proposed policies and their political feasibility.
} 
intertemporal welfare function, suppose the social decision is based on maximizing a two-period utility function of the following form:

$$
U\left[c_{t}, c_{t+1}\right]=u\left(c_{t}\right)+\frac{1}{1+\rho} E\left[u\left(c_{t+1}\right)\right]
$$

where $1 /(1+\rho)$ is the "discount factor" corresponding to $e^{-\rho t}$ in Eq. 1, $E[\bullet]$ represents the expected value of the argument as of time $t$, and $c_{t}$ and $c_{t+1}$ are consumption at times $t$ and $t+1$ respectively. Then if agents are able at time $t$ to purchase an asset (i.e., make an investment) that has an (uncertain) payoff $x_{t+1}$ in the future, the basic rule for the pricing of that asset will be

$$
p_{t}=E\left[\frac{1}{1+\rho} \frac{u^{\prime}\left(c_{t+1}\right)}{u^{\prime}\left(c_{t}\right)} x_{t+1}\right]
$$

This is simply the first-order condition for solution to the problem of maximizing $U$ in Eq. 2. The issues of concern to us can be illustrated without loss of generality by making the common simplifying assumption that $u$ has the form of the "constant relative risk aversion" type, namely

$$
u(c)=\frac{c^{1-\eta}-1}{1-\eta}
$$

where the parameter $\eta$ is the "coefficient of relative risk aversion." The marginal utility of consumption is given by $u^{\prime}[c]=c^{-\eta}$, which is decreasing in $c$ provided $\eta$ is positive. In the absence of uncertainty, it is easy to show that Eqs. 3 and 4 yield a formula for the market interest or discount rate given by

$$
1+r=(1+g)^{\eta}(1+\rho) \Rightarrow r \approx \rho+\eta g
$$

where $g$ is the rate of growth of consumption, with the approximation holding for small $\rho$ and $g$. By analogy with short-term financial calculations, it is typically asserted that future incomes and consumption should be discounted at the interest rate $r$ (in contrast to utility, which is discounted at the rate $\rho$ ). That is, $\$ Y$ at a time $N$ years from now has a present value of only $\$ Y e^{-r N}$ for continuous time models, or $\$ Y(1+r)^{-N}$ for annual calculations in discrete-time models. With $r$ greater than zero, this becomes the basis for the reduced importance of distant-future outcomes in economic calculations.

This shrinkage of future values is not an inevitable consequence of Eq. 5. It has been noted before by Tol (1994), Amano (1997), and Dasgupta et al. (1999) that if environmental damage is sufficiently great so as to reduce consumption in the future, then $g$ may be negative and the discount rate will actually be less than the pure rate of time preference. A sufficiently negative $g$ could even make $r$ negative in this situation. In addition, Eq. 5 needs modification if the economy consists of multiple goods with different growth rates of consumption. If we define the economy to include environmental services, the proper discount rate for evaluating investments in environmental protection will be considerably lower than $r$, and possibly even negative, as long as the elasticity of substitution in demand between produced goods and environmental services is low and the produced goods sector grows faster than the environmental services sector (which may be constant or even declining) (Hoel and Sterner 2007). 
When uncertainty enters the picture, Eq. 5 is no longer valid. In the real world, multiple interest rates and a variety of assets that reflect varying degrees of risk are observed. There is no single "market" discount rate that embodies the return on investment. The importance of this simple empirical fact for climate policy analysis has been pointed out by Howarth (2003), and a number of economists have begun to explore the consequences of uncertainty for discounting (e.g. Newell and Pizer 2003; Ludwig et al. 2005; Howarth 2009; Howarth and Norgaard 2007; Sandsmark and Vennemo 2007; Pesaran et al. 2007). In particular, the discount rate (or expected return) attached to a particular investment has to take into account the covariance between the asset's return and overall consumption. One version of this general relationship is

$$
E\left[r^{i}\right]=r^{f}-\frac{\operatorname{cov}\left[u^{\prime}\left(c_{t+1}\right), r_{t+1}^{i}\right]}{E\left[u^{\prime}\left(c_{t+1}\right)\right]}
$$

where $E\left[r^{i}\right]$ is the expected market discount rate for asset of type or risk class $i$ and $r^{f}$ is the risk-free discount rate. Equation 6 requires some interpretation, because $E\left[r^{i}\right]$ moves in the opposite direction as the price of asset $i$, and the marginal utility of consumption $u^{\prime}$ decreases as consumption increases. Cochrane (2005, pp 13-14) puts it this way:

Investors do not like uncertainty about consumption. If you buy an asset whose payoff covaries positively with consumption, one that pays off well when you are already feeling wealthy, and pays off badly when you are already feeling poor, that asset will make your consumption stream more volatile. You will require a low price to induce you to buy such an asset. If you buy an asset whose payoff covaries negatively with consumption, it helps to smooth consumption and so is more valuable than its expected payoff might indicate. Insurance is an extreme example. Insurance pays off exactly when wealth and consumption would otherwise be low-you get a check when your house burns down. For this reason, you are happy to hold insurance, even though you expect to lose money-even though the price of insurance is greater than its expected payoff discounted at the risk-free rate. ${ }^{4}$

In the particular case in which $\left(c_{t+1} / c_{t}\right)$ is lognormally distributed, with $E\left[\ln \left(c_{t+1} /\right.\right.$ $\left.\left.c_{t}\right)\right]=g$ and $\operatorname{Var}\left[\ln \left(c_{t+1} / c_{t}\right)\right]=\sigma^{2}$, the risk-free rate can be expressed in terms of the underlying parameters as ${ }^{5}$

$$
r^{f}=\rho+\eta g-\frac{1}{2} \eta^{2} \sigma^{2}
$$

\footnotetext{
${ }^{4}$ Or, consider the case of equities. Equities have high returns when consumption is high, so the covariance between the equity discount rate and the marginal utility of consumption is negative (because the marginal utility of consumption is lower when consumption is high). Hence the equity discount rate is higher than the risk-free rate because of the negative sign on the covariance term in Eq. 6.

${ }^{5} \mathrm{An}$ expository derivation is given in Mehra (2003).
} 
where the third term on the right side of the equation is attributable to precautionary savings. Examination of Eqs. 6 and 7 therefore shows quite clearly that "the" discount rate under uncertainty is quite different from the "Ramsey rule" discount rate given by Eq. 5. Even if the rate of growth of consumption is positive on average, considerations of precautionary saving and insurance can lower the discount rate appropriate for valuing climate protection investments (Howarth 2009).

Uncertainty about the underlying structure of the interaction between climate change and the economy creates additional problems for the discounted utility framework. In a series of pathbreaking papers, Weitzman (2007a, b, 2009) has shown that climate catastrophes with low but unknown probabilities and very high damages dominate discounting considerations in formulating a rational policy. This fundamental challenge to the standard IAM approach will be discussed in the concluding section.

Finally, it should be noted that there are serious empirical problems with all of the discounting formulas exemplified by Eqs. 5-7. Plausible and/or historical values of the parameters of these equations (the coefficient of relative risk aversion, the growth rate and variance of consumption, the covariance between returns and the marginal utility of consumption, and the subjective rate of time preference) do not yield discount rates that match the rates which are observed in the market. These anomalies go by names such as "the equity premium puzzle" and "the risk-free rate puzzle," and they show up strongly not only in data for the US, but also in data for other countries with well-developed asset markets (Campbell 2003; Mehra and Prescott 2003). Despite an enormous amount of effort by the best economists to resolve these paradoxes (literally hundreds of scholarly papers have been published on these puzzles), there is no professional consensus on how they might be resolved. These paradoxes present the same kind of challenge to the conventional economic theory of discounting as the Michelson-Morley experiment presented to Newtonian physics. It is surely dubious for climate policy analysis to rely exclusively on a model that faces unexplained empirical challenges to its fundamental theory. As Mehra and Prescott (who originally discovered the equity premium puzzle 1985) comment,

The puzzle cannot be dismissed lightly, since much of our economic intuition is based on the very class of models that fall short so dramatically when confronted with financial data. It underscores the failure of paradigms central to financial and economic modeling to capture the characteristic that appears to make stocks comparatively so risky. Hence the viability of using this class of models for any quantitative assessment, say, for instance, to gauge the welfare implications of alternative stabilization policies, is thrown open to question (Mehra and Prescott 2003, p. 911).

Mehra and Prescott were referring to policies for macroeconomic stabilization, but their admonition applies equally to the use of IAMs to guide climate policy.

\section{Predicting the unpredictable and pricing the priceless}

IAMs analyze the costs and benefits of climate mitigation. Cost-benefit analysis assumes that costs and benefits can be expressed in monetary terms with a reasonable degree of confidence. At least in principle, the costs of environmental protection 
consist of well-defined monetary expenditures (although there are significant problems in the standard approach to projecting mitigation costs, as discussed in the next section). The benefits of environmental protection, however, are generally more difficult to quantify. In the case of climate change, economists confront a double problem; the benefits of mitigation are intrinsically unpredictable and unpriceable.

The unpredictability of climate outcomes reflects, in part, what we do not know, because the effects of climate change are quite likely to be non-marginal displacements that put us outside the realm of historical human experience. Unpredictability is reflected in what we do know as well. We know that the Earth's climate is a strongly nonlinear system that may be characterized by threshold effects and chaotic dynamics. Under such conditions, forecasts are necessarily indeterminate; it becomes appropriate to say that within a broad range of possible outcomes, anything can happen. IAMs, for the most part, do not incorporate this approach to uncertainty, but instead adopt best guesses about likely outcomes (Kelly and Kolstad 1999; Tol 2002a; Manne 2004; Mendelsohn 2004; Nordhaus 2007a). The Stern Review (2006) represents an advance over standard practice in this respect, employing a Monte Carlo analysis to estimate the effects of uncertainty in many climate parameters. As a result, the Stern Review finds a substantially greater benefit from mitigation than if it had simply used "best guesses."

But underneath one layer of assumptions lies another. Even if we assume precision in predicting climate impacts, the problem of assigning meaningful monetary values to human life, health, and natural ecosystems still remains. This problem affects all cost-benefit analysis. Because a numerical answer is required, environmental economists have long been in the business of constructing surrogate prices for seemingly priceless values. The results are not impressive. Should we estimate the value of human life on the basis of the small wage differentials between more and less dangerous jobs, as Clinton administration analysts assumed? Or, should we rely on responses to long questionnaires asking people how much they would pay to avoid small risks of death under abstract hypothetical scenarios, as the Bush administration did ${ }^{6}$ Should we value ecosystems according to what people living nearby report they are willing to pay to preserve their scenic vistas or their favorite large animals? A non-economist could be forgiven for assuming that these are rhetorical questions. Yet these approaches are regularly applied in policy analyses to estimate monetary values for health and environmental benefits (Diamond and Hausman 1994; Hanemann 1994; Portney 1994).

Should the value of a human life depend on individual or national income levels? Should nature located in a rich country be worth more than if it is located in a poor country? Remarkably, economists often answer "yes" to both of these disturbing questions. Values of human life differentiated by national income made a brief and unwelcome appearance in the IPCC's Second Assessment Report (1996) but appeared to be banished by the time of the Third Assessment Report (2001). Similar values, however, continue to appear in the economics literature, making their way into IAMs (Tol 2002b; Bosello et al. 2006), where the lives of citizens of rich countries are often assumed to be worth much more than those of their poorer counterparts.

${ }^{6}$ See Ackerman and Heinzerling (2004), especially Chapter 4, pp. 75-81. 
Income bias is inherent to the process of valuation. When asked how much they are willing to pay to protect some small part of the natural world (a technique called contingent valuation), individuals' responses cannot help but reflect how much they are actually able to afford. While this survey method may provide plausible information about subjective values for local amenities, such as parks that neighborhoods will pay for, it is of little use in a complex, interdependent world where essential ecosystem services are not always visible or local and where incomes and information are very unequally distributed.

Indeed, one of the anomalies of the IAMs is the frequency with which economists have discovered benefits from near-term warming. Even if benefits are thought to disappear after a few degrees, or a few decades, a high discount rate ensures that the years of benefits loom large in present value terms when compared to the more remote and heavily discounted later years of damages.

For example, Nordhaus long maintained that there is a substantial subjective willingness to pay for warmer weather on the part of people in cold, rich countries. He observes that US households spend more on outdoor recreation in the summer than in the winter and, on the basis of that slim empirical foundation, concludes that subjective enjoyment of the climate worldwide would be maximized at a year-round average temperature of $20^{\circ} \mathrm{C}$ (Nordhaus and Boyer 2000). This is well above the current global average; it is approximately the temperature of Houston and New Orleans in the US, or Tripoli in Libya. There are many people who live in areas hotter than Houston, but they are generally much poorer than the people who live in areas colder than Houston. Thus if willingness to pay is indeed limited by ability to pay, there is a large net global willingness to pay for warming. In the 2000 version of DICE, this factor outweighed all damages and implied net benefits from warming until the middle of this century (Nordhaus and Boyer 2000). However, that oddity of the earlier DICE has been criticized (Ackerman and Finlayson 2006) and the latest DICE (of 2007), while still including and monetizing subjective gains for warming up to $20^{\circ} \mathrm{C}$ along with other costs and benefits, no longer allows any region to have overall net benefits from warming (Nordhaus 2007b).

A more quantifiable, but equally contestable, benefit from warming involves the impacts of warming on agriculture. Early studies of climate impacts suggested substantial agricultural gains from warming, as a result of longer growing seasons in high latitudes and the effects of $\mathrm{CO}_{2}$ fertilization on many crops. Mendelsohn et al. (2000), and Tol (2002a) incorporated large estimated agricultural gains from early stages of warming. Successive studies, however, have steadily reduced the estimated benefits. Outdoor experiments have shown smaller benefits from $\mathrm{CO}_{2}$ fertilization than earlier experiments conducted in greenhouses (Intergovernmental Panel on Climate Change 2007b). Recent research predicts that the negative effects of groundlevel of ozone, which is produced by the same fossil fuel combustion processes that emit $\mathrm{CO}_{2}$, may offset the impacts of a longer growing season and $\mathrm{CO}_{2}$ fertilization and lead to a small net decrease in agricultural productivity in the US (Reilly et al. 2007). Another recent study finds that the market value of non-irrigated farmland in the US is highly correlated with climate variables. The optimum value occurs at roughly the current US average temperature with somewhat more than the current US average rainfall. This study's projections of climate change to the end of the century imply substantial losses in farm value, due primarily to crop damage from the increase in the number of days above $34^{\circ} \mathrm{C}$ (Schlenker et al. 2006). 
As these examples of potential benefits suggest, there is a significant degree of subjective judgment involved in estimating the value of climate damages; but IAMs are completely dependent on the shape of their assumed damage functions. It is conventional to assume that damages are a quadratic function of temperature increases, based, perhaps, on the common notion that damages should rise faster than temperature. But why a quadratic function in particular? The Stern Review (2006) made the exponent on the damage function a Monte Carlo parameter, ranging from 1 to 3 (damages ranged from a linear to a cubic function of temperature). Even though Stern's modal estimate was only 1.3, the cases with a higher exponent had a large effect on the outcome. In later sensitivity analyses in response to critics, the Stern Review researchers showed that if the assumed damages were a cubic function of temperature, the result was an enormous increase in the estimate of climate damages, changing their prediction by more than $20 \%$ of world output (Dietz et al. 2007).

In short, unlike the scientific modeling involved in GCMs, the results of IAMs are tied to subjective judgments about the shape of the damage function as we move into temperature regimes that are unknown in human or recent planetary history.

\section{Technology forecasts: not so bright}

IAMs simulate the macroeconomic impacts of climate policies designed to achieve particular emissions trajectories. IAMs typically estimate costs as an annual percentage loss in GDP. IAMs cannot forecast job losses-the issue most politicians demand clarity on-because supply equals demand in every market (including the labor market) by design. The IPCC's Fourth Assessment Report summarizes the range of cost estimates for a low stabilization target (445-535 ppm- $\mathrm{CO}_{2}$ equivalent) and finds that for all available studies, costs do not exceed $3 \%$ of global GDP in the medium term (i.e., 2030). For higher stabilization targets, estimates range from $2-2.5 \%$ of GDP (Intergovernmental Panel on Climate Change 2007c). Is 3\% of global GDP worth sacrificing to avoid the damages of climate change? In the US, losing 3\% of GDP in 2007 would mean reverting to the per capita income Americans enjoyed in 2006. In dollar terms, it is equivalent to spending $\$ 350$ billion per year or $\$ 1,170$ per capita. Whether we think $\$ 350$ billion per year is too high a price to pay to avoid climate change depends on the severity of the climate damages we anticipate. Given the problems inherent in IAM estimates of climate damages, it is impossible to conclude from IAMs that $3 \%$ of GDP is, or is not, worth spending.

What we do know is that there is good reason to believe that IAMs overestimate the costs of achieving stabilization targets. Estimating mitigation costs in dollar terms is more straightforward, in principle, than measuring mitigation benefits. The adoption of energy-efficient equipment, appliances, industrial processes, and automobiles, as well as more widespread use of combined heat and power technologies, wind energy systems, solar panels, and other measures for reducing emissions all involve purchases of marketed goods and services whose attendant cash flows can be easily counted. The evolution of these technologies is uncertain, however, particularly over the long time periods involved in climate modeling. Forecasts of mitigation costs, therefore, depend on assumptions about the pace of development of new (and existing) technologies and their costs. 
IAMs typically adopt conservative assumptions about the pace of technical change, abstracting away from the potential for learning-by-doing and the positive role public policy can play in steering investment choices and promoting technical change. Most IAMs assume a predictable annual rate of productivity improvement in energy use, and/or a predictable rate of decrease in emissions per unit of output. Thus a paradoxical result emerges from the models' overly mechanistic structure. Because climate change is a long term crisis, and predictable, inexorable technological change will make it easier and cheaper to reduce emissions in the future, it seems better to wait before addressing the problem of climate change. Hence, most IAMs advocate a cautious approach that involves only modest early action to limit emissions with gradually increasing limits over time. Alternative models that assume endogenous technical change reach different conclusions and frequently recommend more aggressive carbon abatement policies, with results varying according to how the models are specified (e.g., Goulder and Schneider 1999; Gerlagh 2007; for recent surveys of this literature, see the special issue of Resource and Energy Economics edited by Carraro et al. 2003; Edenhofer et al. 2006, and the special issue of The Energy Journal IAEE IAEE (2006) in which it appears; and Gillingham et al. 2007).

Furthermore, most IAMs exclude the possibility for "no-regrets" optionsinvestments that could reduce emissions without imposing significant opportunity costs. These options do exist, largely in the area of improved energy efficiency (Intergovernmental Panel on Climate Change 1996; Interlaboratory Working Group 2000; Lovins 2005; Elliott et al. 2006; Shipley and Elliott 2006; Laitner et al. 2006; McKinsey Global Institute 2007). IAMs ignore these opportunities because they assume that the economy functions on its production possibilities frontier. This means that businesses and consumers behave with perfect rationality to achieve their objectives and are successful in optimizing their behaviors. It is increasingly wellunderstood in the economics literature, however, that businesses do not exploit every opportunity for profit. There are many opportunities to increase efficiency, reduce costs, and improve productivity that are not taken up due to organizational and institutional constraints (DeCanio et al. 2000, 2001). Incomplete information about technologies, societal norms, difficulty in capitalizing on energy efficient investments, and distorted market prices for energy are all well known examples of barriers to the adoption of more energy efficient measures. Well-designed climate policy can play a decisive role in removing these barriers. If technical change is socially determined and its results are path dependent, we can only arrive in the future with new energy technology choices available if we start conscious, carefully planned development of those technologies today. Waiting for the deus ex machina of technical change, the misleading option suggested by IAMs, will ensure that we face fewer options in the future at significantly higher costs. ${ }^{7}$

\footnotetext{
${ }^{7}$ Some zero-cost adaptations to climate change may also exist. However, the IPCC's Fourth Assessment Report notes that " $[\mathrm{m}]$ ost studies of specific adaptation plans and actions argue that there are likely to be both limits and barriers to adaptation as a response to climate change. The U.S. National Assessment (2001), for example, maintains that adaptation will not necessarily make the aggregate impacts of climate change negligible or beneficial, nor can it be assumed that all available adaptation measures will actually be taken" (2007b, p. 733).
} 
There are more satisfying ways of mapping cost-effective technologies into climate models that yield different impacts. The costs of climate policy depend heavily on how technology and its benefits over time are characterized (Worrell et al. 2003). For example, Krause et al. (2002, 2003) include the efficiency-improving possibilities documented in the "5-lab study" (Interlaboratory Working Group 2000) to arrive at least-cost estimates of the economic costs of emissions reduction. Policy assessments typically include savings on energy bills and lower compliance costs, such as the benefits of new energy technologies, but overlook the potential for "non-energy" benefits, such as lower maintenance costs, increased production yields, safer work conditions, positive spill-over effects, and economies of scale and scope. These benefits increase the return on energy-related investments; if recognized, firms and consumers may become more willing to adopt or invest in them (Finman and Laitner 2001). These benefits may, in some cases, exceed the associated energy bill savings (Worrell et al. 2003).

The productivity-enhancing effects of investing in these technologies can help offset any drag on the economy imposed by higher fossil-fuel prices. New technologies can stimulate new investment, save consumers money, stimulate productive research and development with spill-over benefits for other sectors and positive multiplier effects, and help to reduce energy imports and increase technology exports. Massive public investment in military technology since World War II led to the widespread adoption of jet aircraft, semi-conductors, and the Internet by the private sector and is partly responsible for the technological advantage the US holds globally. In the early 1980s, US companies led the world in wind energy technologies. Today, we import those technologies (Goodstein 2007). As the rest of the world moves forward with climate policy, the US risks losing its technological advantage unless it charts (and funds) a careful and deliberate new technology path.

\section{Insurance, precaution, and the contribution of climate economics}

In the three preceding sections, we argued that most IAMs rely on an analytical framework that privileges immediate, individual consumption over future-oriented concerns; that the benefits, or avoided damages, from climate mitigation are both unpredictable in detail and intrinsically non-monetizable; and that the conventional economic view of technology misrepresents the dynamic, socially determined nature of technical change. Not much is left, therefore, of the standard economic approach and its ambitions to perform a complete cost-benefit analysis of climate policy options. In light of these criticisms, how should we think about policy options and the economics of climate change?

It should be emphasized that the optimal control approach to climate policy embodied in Eq. 1 above is not the only one proposed in the literature. For example, the early growth literature proposed the notion of the "Golden Rule" steady state growth path (Solow 1970). In this simple model with the savings rate as the only policy variable, optimal growth is the path yielding the highest level of consumption per capita among all sustainable growth paths. Sustainable growth, in this context, is a path that does not sacrifice the consumption of future generations by consuming society's capital (including natural capital) for the benefit of the present generation. In such a model, the market rate of interest is equal to the rate of growth of consumption. 
If the "willingness to pay" on the part of future generations to avert environmental destruction is proportional to income, then the effective discount rate on the Golden Rule growth path is zero (DeCanio 2003). The notion of the Golden Rule growth path has been generalized to "Green Golden Rule" growth, with different implications for the discount rate depending on the assumptions made about the interaction between the environment and the market economy (Chichilnisky et al. 1995; Bella 2006).

A present generation that cares nothing about the fate of future generations will do nothing to preserve the stability of the Earth's climate, and no economic calculations can show otherwise. But whether and how much people care about the future can be represented in various ways - through the rate of subjective time preference in optimal growth models, through the weighting of different generations' welfare in overlapping generations models (Howarth and Norgaard 1992; Howarth 1996), through thought experiments in which the generations are able to transact with one another (DeCanio and Niemann 2006) - and the results, not unexpectedly, will reflect the depth and strength of the intergenerational ties. The upshot of these alternative ways of characterizing the intergenerational decision-making problem is that the normative assumptions that are made about how future generations are treated are as important as the technical details. Not having happened yet, the future is unobservable; moreover, there are no reliable, universally accepted economic laws that shape our understanding of the future in the way that the laws of natural science do for the physical reality of climate change. When it comes to economics, there is no escape from value-laden assumptions about the future. Furthermore, consciousness and intergenerational concern are influenced by social and political discourse. In the case of climate policy where fundamental values and ethical principles are at stake, it is an abdication of responsibility for economists to act as if peoples' preferences are simply given and fixed.

One of the most interesting new areas of economic theory as applied to climate involves the analysis of uncertainty. If the probabilities of a range of possible outcomes were known, as in casino games or homework exercises in statistics classes, then there would be no need for a new theory; it would be a straightforward matter to calculate the expected value of climate outcomes and economic consequences. However, this is a poor model for many of the most important climate problems. When probability distributions themselves are unknown, the problem of uncertainty is much more difficult to address. The combination of unknown probability distributions and potentially disastrous outcomes provides a strong motivation for precautionary policy, as insurance against those disasters. As noted in a recent review of scientific knowledge about potential "tipping elements" of earth systems, "[s]ociety may be lulled into a false sense of security by smooth projections of global change....present knowledge suggests that a variety of tipping elements could reach their critical point within this century under anthropogenic climate change" (Lenton et al. 2008; see also Committee on Abrupt Climate Change 2002). Uncertainty about the climate sensitivity, the key parameter in assessing the probability for ranges of potential equilibrium global temperature changes, is intrinsically resistant to improvements in scientific understanding of particular climate processes (Roe and Baker 2007).

Several economists working at the theoretical frontier have proposed new ways of dealing with these kinds of deep uncertainties (e.g., Gjerde et al. 1999; Chichilnisky 2000; Hall and Behl 2006; Dasgupta 2008; Weitzman 2007a, b, 2009). For example, 
Martin Weitzman has developed a model applicable to financial markets as well as climate change. People learn about the world through repeated experiences, but if the relevant structure of the world is changing rapidly or greatly enough, only the most recent experiences can be relied on, and everyone is effectively engaged in Bayesian estimation from a finite sample. In this circumstance, the best available estimate of the true probability distribution has fat tails. Because people are riskaverse, the attempt to avoid the disturbing possibility of very large losses dominates policy decisions. The result, Weitzman argues, is that fine-tuning the estimates of the most likely level of climate damages is irrelevant; what matters is how bad and how likely the worst extremes of the possible outcomes are. There is little doubt that the 95th percentile, or 98th percentile, of possible adverse climate outcomes over the next century (to pick two arbitrary points out in the tail of the distribution) would look like the devastation of the planet in a science-fiction dystopia, not like a matter for carefully weighing costs and benefits.

Intuitively, this is the same logic that motivates the purchase of insurance, a precautionary decision that people make all the time. The most likely number of house fires that you will experience next year, or even in your lifetime, is zero. Very few homeowners find this a compelling reason to go without fire insurance. Similarly, healthy young adults often buy life insurance to protect their children's future in the worst possible case. Residential fires, and deaths of healthy young adults, have annual probabilities measured in the tenths of $1 \%$. In other words, people routinely insure themselves against personal catastrophes that are much less likely than worst-case climate catastrophes for the planet. ${ }^{8}$

How would this perspective change our approach to climate economics and policy choices? Economics would find itself in a humbler role, no longer charged with determining the optimal policy. Instead, a discussion of scientific information about catastrophic possibilities and consequences would presumably lead to the choice of maximum safe targets, expressed in terms of allowable increases in temperature and $\mathrm{CO}_{2}$ levels. Once safe targets have been established, there remain the extremely complex and intellectually challenging tasks - for which the tools of economics are both appropriate and powerful-of determining the least-cost global strategy for achieving those targets, designing policies that effectively and with confidence meet the targets, ${ }^{9}$ and sharing responsibility for the costs and implementation of that strategy.

This cost-effectiveness task, despite its daunting difficulty, is more limited than the cost-benefit analysis attempted by IAMs - and the reduced scope avoids many of the problems we have discussed. Discounting is less of an issue, because the costs of mitigation and adaptation, while still spread out in time, generally occur much sooner than the full range of anticipated damages. Precise estimation and monetization of

\footnotetext{
${ }^{8}$ Ironically, given the subsequent focus on cost-benefit analysis, one of the precursors of current IAMs appeared in a book titled, Buying Greenhouse Insurance: The Economic Costs of $\mathrm{CO}_{2}$ Emissions Limits (Manne and Richels 1992).

${ }^{9}$ The "tolerable windows approach" is one promising development in this direction. This methodology "concentrates on a few key attributes (e.g., acceptable impacts and costs) and provides an envelope for future action. Which course should be taken within the envelope?" (Toth et al. 2003, pp. 54-55). A special issue of Climatic Change (2003, nos. 1-2; see Toth 2003) contains a number of papers embodying this approach.
} 
benefits is no longer necessary, because cost-effectiveness analysis takes the benefits side as fixed (or, in the language of economics, assigns an infinite shadow price to the constraint of meeting the chosen target-another way of saying that cost calculations are not allowed to override the prior choice of a safe standard).

There are two take-home messages here. The first is that policy makers and scientists should be skeptical of efforts by economists to specify optimal policy paths using the current generation of IAMs. These models do not embody the state of the art in the economic theory of uncertainty, and the foundations of the IAMs are much shakier than the general circulation models that represent our best current understanding of physical climate processes. Not only do the IAMs entail an implicit philosophical stance that is highly contestable, they suffer from technical deficiencies that are widely recognized within economics. Second, economists do have useful insights for climate policy. While economics itself is insufficient to determine the urgency for precautionary action in the face of low-probability climate catastrophes, or make judgments about intergenerational and intragenerational justice, it does point the way towards achieving climate stabilization in a cost-effective manner. IAMs cannot, however, be looked to as the ultimate arbiter of climate policy choices.

Acknowledgements We have benefited from comments by John Gliedman, Sarah A. Kruse, Rajnish Mehra, Richard B. Norgaard, Catherine S. Norman, Martin Weitzman, and two referees. Responsibility for any errors is ours.

Open Access This article is distributed under the terms of the Creative Commons Attribution Noncommercial License which permits any noncommercial use, distribution, and reproduction in any medium, provided the original author(s) and source are credited.

\section{References}

Ackerman F, Finlayson IJ (2006) The economics of inaction on climate change: a sensitivity analysis. Clim Policy 6:509-526

Ackerman F, Heinzerling L (2004) Priceless: on knowing the price of everything and the value of nothing. The New Press, New York

Amano A (1997) On some integrated assessment modeling debates. Paper presented at IPCC AsiaPacific Workshop on Integrated Assessment Models, United Nations University, Tokyo, March $10-12$

Bella G (2006) A blueprint for optimal intertemporal consumption under environmental constraints: the modified green golden rule. Available at SSRN: http://ssrn.com/abstract=936879

Bosello F, Roson R, Tol RSJ (2006) Economy-wide estimates of the implications of climate change: human health. Ecol Econ 58:579-591

Broome J (1994) Discounting the future. Phil Pub Aff 23:128-156

Buffett B, Archer D (2004) Global inventory of methane clathrate: sensitivity to changes in the deep ocean. Earth Planet Sci Lett 227:185-199

Campbell JY (2003) Consumption-based asset pricing. In: Constantinides GM, Harris M, Stultz R (eds) Handbook of the economics of finance. Elsevier, Amsterdam, pp 804-887

Carraro C, Gerlagh R, van der Zwaan B (2003) Endogenous technical change in environmental macroeconomics. Resour Energy Econ 25:1-10

Chichilnisky G (2000) An axiomatic approach to choice under uncertainty with catastrophic risks. Resour Energy Econ 22:221-231

Chichilnisky G, Heal G, Beltratti A (1995) The green golden rule. Econ Lett 49:175-179

Cline WR (1992) The economics of global warming. Institute for International Economics, Washington, DC

Cochrane JH (2005) Asset pricing, revised edn. Princeton University Press, Princeton 
Committee on Abrupt Climate Change, National Research Council (2002) Abrupt climate change: inevitable surprises. National Academies, Washington, DC

Committee on Analysis of Global Change Assessments, National Research Council (2007) Analysis of global change assessments: lessons learned. National Academies, Washington, DC

Dasgupta P (2008) Discounting climate change. J Risk Uncertainty 37:141-169

Dasgupta PS, Heal GM (1979) Economic theory and exhaustible resources. Cambridge, Cambridge Univ Press

Dasgupta P, Mäler KG, Barrett S (1999) Intergenerational equity, social discount rates, and global warming. In: Portney PR, Weyant JP (eds) Discounting and intergenerational equity. Resources for the Future, Washington, DC, pp 51-78

DeCanio SJ (2003) Economic analysis, environmental policy, and intergenerational justice in the Reagan administration: the case of the Montreal protocol. Int Environ Agreements 3:299-321

DeCanio SJ, Niemann P (2006) Equity effects of alternative assignments of global environmental rights. Ecol Econ 56:546-559

DeCanio SJ, Dibble C, Amir-Atefi K (2000) The importance of organizational structure for the adoption of innovations. Manage Sci 46:1285-1299

DeCanio SJ, Dibble C, Amir-Atefi K (2001) Organizational structure and the behavior of firms: implications for integrated assessment. Clim Change 48:487-514

Diamond PA, Hausman JA (1994) Contingent valuation: is some number better than no number? J Econ Perspect 8:45-64

Dietz S, Hope C, Stern N, Zenghelis D (2007) Reflections on the Stern review (1): a robust case for strong action to reduce the risks of climate change. World Econ 8:121-168

Edenhofer O, Lessmann K, Kemfert C, Grubb M, Köhler J (2006) Induced technological change: exploring its implications for the economics of atmospheric stabilization: synthesis report from the innovation modeling comparison project. The Energy Journal, Endogenous Technological Change and the Economics of Atmospheric Stabilisation Special Issue 27:57-107

Elliott RN, Langer T, Nadel (2006) Reducing oil use through energy efficiency: opportunities beyond light cars and trucks. American Council for an Energy Efficient Economy, Washington, DC

Finman H, Laitner JA (2001) Industry, energy efficiency, and productivity improvements in proceedings of the 2001 ACEEE summer study on energy efficiency in industry. American Council for an Energy Efficient Economy, Washington, DC

Frederick S, Loewenstein G, O’Donoghue T (2002) Time discounting and time preference. J Econ Lit XL:351-401

Gerlagh R (2007) Measuring the value of induced technological change. Energy Policy 35:5287-5297

Gillingham K, Newell RG, Pizer WA (2007) Modeling endogenous technological change for climate policy analysis. Resources for the Future, Washington DC

Gjerde J, Grepperud S, Kverndokk S (1999) Optimal climate policy under the possibility of a catastrophe. Resour Energy Econ 21:289-317

Goodstein E (2007) Economics and the environment, 5th edn. Wiley, New York, pp 409-411

Goulder LH, Schneider SH (1999) Induced technological change and the attractiveness of CO2 abatement policies. Resour Energy Econ 21:211-253

Hall DC, Behl RJ (2006) Integrating economic analysis and the science of climate instability. Ecol Econ 57:442-465

Hanemann WM (1994) Valuing the environment through contingent valuation. J Econ Perspect 8:19-43

Hoegh-Guldberg O, Mumby PJ, Hooten AJ, Steneck RS, Greenfield P, Gomez E, Harvell CD, Sale PF, Edwards AJ, Caldeira K, Knowlton CM, Eakin R, Iglesias-Prieto R, Muthiga N, Bradbury RH, Dubi A, Hatziolos ME (2007) Coral reefs under rapid climate change and ocean acidification. Science 318:1737-1742

Hoel M, Sterner T (2007) Discounting and relative prices. Clim Change 84:265-280

Howarth RB (1996) Climate change and overlapping generations. Contemp Econ Policy 14:100-111

Howarth RB (1998) An overlapping generations model of climate-economy interactions. Scand J Econ 100:575-591

Howarth RB (2003) Discounting and uncertainty in climate change policy analysis. Land Econ 79:369-381

Howarth RB (2009) Discounting, uncertainty, and revealed time preference. Land Econ 85:24-40

Howarth RB, Norgaard RB (1992) Environmental valuation under sustainable development. Am Econ Rev 82:473-477

Howarth RB, Norgaard RB (2007) $\mathrm{CO}_{2}$ emissions: getting bang for the buck. Science 318:1865-1866

Intergovernmental Panel on Climate Change (1996) In: Bruce JP, Lee H, Haites EF (eds) Climate change 1995: economic and social dimensions of climate change, contribution of working group 
III to the second assessment report of the intergovernmental panel on climate change. Cambridge Univ Press, Cambridge, UK

Intergovernmental Panel on Climate Change (2001) In: Metz B, Davidson O, Swart R, Pan J (eds) Climate change 2001: contribution of working group III to the third assessment report of the intergovernmental panel on climate change. Cambridge Univ Press, Cambridge, UK

Intergovernmental Panel on Climate Change (2007a) Summary for policymakers. In: Solomon S, Qin D, Manning M, Chen Z, Marquis M, Averyt KB, Tignor M, Miller HL (eds) Climate change 2007: the physical science basis, contribution of working group I to the fourth assessment report of the intergovernmental panel on climate change. Cambridge Univ Press, Cambridge, UK and New York

Intergovernmental Panel on Climate Change (2007b) In: Parry ML, Canziani OF, Palutikof JP, van der Linden PJ, Hanson CE (eds) Climate change 2007: impacts, adaptation and vulnerability, contribution of working group II to the fourth assessment report of the intergovernmental panel on climate change. Cambridge Univ Press, Cambridge, UK, pp 273-314

Intergovernmental Panel on Climate Change (2007c) Summary for policymakers. In: Metz B, Davidson OR, Bosch PR, Dave R, Meyer LA (eds) Contribution of Working group III to the fourth assessment report of the intergovernmental panel on climate change. Cambridge Univ Press, Cambridge, UK, pp 9-12

Interlaboratory Working Group on Energy-Efficient and Clean-Energy Technologies (2000) Scenarios for a clean energy future. Oak Ridge Natl Lab and Lawrence Berkeley Natl Lab, Oak Ridge, TN and Berkeley, CA. Available at: http://www.ornl.gov/sci/eere/cef/

International Association for Energy Economics (IAEE) (2006) Endogenous technological change and the economics of atmospheric stabilisation special issue. Energy J 27:1-276

Kahneman D, Tversky A (eds) (2000). Choices, values, and frames. Russell Sage Foundation, New York

Kelly DL, Kolstad CD (1999) Integrated assessment models for climate change control. In: Folmer H, Tietenberg T (eds) International yearbook of environmental and resource economics 1999/2000: a survey of current issues. Edward Elgar, pp 171-197

Kennedy M, Mrofka D, von der Borch C (2008) Snowball Earth termination by destabilization of equatorial permafrost methane clathrate. Nature 453:642-645

Krause F, DeCanio SJ, Hoerner A, Baer P (2002) Cutting carbon emissions at a profit (part I): opportunities for the United States. Contemp Econ Pol 20:339-365

Krause F, DeCanio SJ, Hoerner A, Baer P (2003) Cutting carbon emissions at a profit (part II): impacts on US competitiveness and jobs. Contemp Econ Pol 21:90-105

Laitner JA, DeCanio SJ, Peters I (2000) Incorporating behavioural, social, and organizational phenomena in the assessment of climate change mitigation options. In: Jochem E, Sathaye J, Bouille D (eds) Society, behaviour, and climate change mitigation. Kluwer Academic, Dordrecht, pp 1-64

Laitner JA, Hanson DA, Mintzer I, Leonard JA (2006) Adapting for uncertainty: a scenario analysis of US technology energy futures. Energy Stud Rev 14:120-135

Lenton TM, Held H, Kriegler E, Hall JW, Lucht W, Rahmstorf S, Schellnhuber J (2008) Tipping elements in the earth's climate system. Proc Natl Acad Sci USA 105:1786-1793

Lovins AB (2005) More profit with less carbon. Sci Am Sept:74-82

Ludwig D, Brock WA, Carpenter SR (2005) Uncertainty in discount models and environmental accounting. Eco Soc 10:13

Manne AS (2004) Perspective Paper 1.2. In: Lomborg B (ed) Global crises, global solutions. Cambridge Univ Press, Cambridge, pp 49-55

Manne AS, Richels RG (1992) Buying greenhouse insurance: the economic costs of $\mathrm{CO}_{2}$ emissions limits. MIT, Cambridge

McKinsey Global Institute (2007) Curbing global energy demand growth: the energy productivity opportunity, pp 1-24. Available at: http://www.mckinsey.com/mgi/publications/Curbing_Global_ Energy/index.asp

Mehra R (2003) The equity premium: why is it a puzzle? Financ Anal J:54-69

Mehra R, Prescott EC (1985) The equity premium: a puzzle. J Monet Econ 15:145-161

Mehra R, Prescott EC (2003) The equity premium in retrospect. In: Constantinides GM, Harris M, Stultz R (eds) Handbook of the economics of finance. Elsevier, Amsterdam, pp 889-938

Mendelsohn R (2004) Perspective paper 1.1. In: Lomborg B (ed) Global crises, global solutions. Cambridge University Press, Cambridge, pp 44-48

Mendelsohn R, Morrison W, Schlesinger ME, Andronova NG (2000) Country-specific market impacts of climate change. Clim Change 45:553-569 
Newell RG, Pizer WA (2003) Discounting the distant future: how much do uncertain rates increase valuations? J Environ Econ Manage 46:52-71

Nordhaus WD (2007a) A review of the stern review on the economics of climate change. J Econ Lit XLV:686-702

Nordhaus WD (2007b) The challenge of global warming: economic models and environmental policy. Available at http://nordhaus.econ.yale.edu/dice_mss_072407_all.pdf

Nordhaus WD, Boyer J (2000) Warming the world: economic models of global warming. MIT, Cambridge

Paltsev S, Reilly JM, Jacoby HD, Gurgel AC, Metcalf GE, Sokolov AP, Holak JF (2007) Assessment of US cap-and-trade proposals. Available at SSRN: http://ssrn.com/abstract=994225

Pesaran H, Pettenuzzo D, Timmermann A (2007) Learning, structural instability, and present value calculations. Econ Rev 26(2-4):253-288

Portney PR (1994) The contingent valuation debate: why economists should care. J Econ Perspect 8:3-17

Ramsey FP (1928) A mathematical theory of saving. Econ J 38:543-559

Reilly J, Paltsev S, Felzer B, Wang X, Kicklighter D, Melillo J, Prinn R, Sarofim M, Sokolov A, Wang C (2007) Global economic effects of changes in crops, pasture, and forests due to changing climate, carbon dioxide, and ozone. Energy Policy 35:5370-5383

Roe GH, Baker MB (2007) Why is climate sensitivity so unpredictable? Science 318:629-632

Sandsmark M, Vennemo H (2007) A portfolio approach to climate investments: CAPM and endogenous risk. Environ Resour Econ 4:681-695

Schellnhuber HJ, Cramer W, Nakicenovic N, Wigley T, Yohe G (eds) (2006) Avoiding dangerous climate change. Cambridge University Press, Cambridge, UK

Schlenker W, Hanemann WM, Fisher AC (2006) The impact of global warming on U.S. agriculture: an econometric analysis of optimal growing conditions. Rev Econ Stat 88:113-125

Shipley AM, Elliott RN (2006) Ripe for the picking: have we exhausted the low hanging fruit in the industrial sector? American Council for an Energy Efficient Economy, Washington, DC, Report No. IE061. Available at: http://www.resourcesaver.org/file/toolmanager/ CustomO16C45F69267.pdf

Solow RM (1970) Growth theory: an exposition. Oxford University Press, New York

Stern N (2006) Stern review on the economics of climate change. Her Majesty's Treasury, London

Tol RSJ (1994) The damage costs of climate change—a note on tangibles and intangibles, applied to DICE. Energy Policy 22:436-438

Tol RSJ (2002a) Estimates of the damage costs of climate change: part I. Benchmark estimates. Environ Resour Econ 21:47-73

Tol RSJ (2002b) Estimates of the damage costs of climate change: part II. Dynamic estimates. Environ Resour Econ 21:135-160, p 157

Toth FL (2003) Integrated assessment of climate protection strategies-guest editorial. Clim Change $56: 1-5$

Toth FL, Mwandosya M (Co-ordinating Lead Authors), Carraro C, Christensen J, Edmonds J, Flannery B, Gay-Garcia C, Lee H, Meyer-Abich KM, Nikitina E, Rahman A, Richels R, Reqiu Y, Villavicencio A, Wake Y, Weyant J (Lead Authors), Byrne J, Lempert R, Meyer I, Underdal A (Contributing Authors), Pershing J, Shechter M (Review Editors) (2001) Decision-making frameworks, chapter 10 of climate change 2001: mitigation, contribution of working group III to the third assessment report of the intergovernmental panel on climate change. Cambridge University Press, Cambridge, UK

Toth FL, Bruckner T, Füssel HM, Leimbach M, Petschel-Held G (2003) Integrated assessment of long-term climate policies: part 1-model presentation. Clim Change 56:37-56

US National Assessment (2001) Climate change impacts on the united states: the potential consequences of climate variability and change. Report for the US Global Change Research Program. Cambridge University Press, Cambridge UK

Weitzman ML (2007a) A review of the Stern review on the economics of climate change. J Econ Lit XLV:703-724

Weitzman ML (2007b) Subjective expectations and asset-return puzzles. Am Econ Rev 97:1102-1130

Weitzman ML (2009) On modeling and interpreting the economics of catastrophic climate change. Rev Econ Stat 91:1-19

Worrell E, Laitner JA, Ruth M, Finman H (2003) Productivity benefits of industrial energy efficiency measures. Energy J 21:1081-1098 